\author{
А. А. Соколянский \\ Северо-Восточный государственный университет \\ (Россия, Магадан) \\ sokol_2001@mail.ru,sokol_2001@outlook.com
}

\title{
ФОНЕМА КАК ВОСХОЖДЕНИЕ: ОСНОВНЫЕ ПОЛОЖЕНИЯ МНОГОУРОВНЕВОЙ ФОНОЛОГИИ*
}

В статье рассмотрены основные положения многоуровневой фонологии русского языка с позиций Московской фонологической школы.

В рамках Московской фонологической школы фактически сложилось два понимания фонологической системы. Традиционное учение предполагало выделение одной фонологической единицы - фонемы (А.А. Реформатский, П.С. Кузнецов, В.Н. Сидоров, Л.Л. Касаткин). Позднее возникла идея о многоуровневой фонологии, согласно которой в соответствии с разными функциями звуковых единиц следует выделять несколько типов фонем (С.И. Бернштейн, Р.И. Аванесов, М.В. Панов). Попытки развить идеи многоуровневой фонологии содержат и работы автора статьи.

Автор приходит к выводу, что наиболее адекватным объекту является многоуровневое описание системы фонетического уровня языка. Предлагается выделять следующие единицы: слог как единицу речевого потока, звуки речи первого и второго рода как единицы речи, звук языка как единицу, промежуточную между языком и речью, дифференциатор, синтагмо-фонему, парадигма-фонему, морфонему как единицы языка. Выделенные единицы соединяются между собой системой чередований.

Ключевые слова: многоуровневая фонология, звук речи, звук языка, дифференциатор, синтагмо-фонема, парадигмо-фонема, морфонема

На самом деле у меня теория некрасивая, в смысле том, что она громоздкая. Я жду: придет кто-то, кто сделает какой-то следующий шаг, что-то извлечет из нее, то, что будет плодотворным. Пр и ди, н е знакомец! А может, я и сам сделаю шаг, пока я еще не умер [Панов 2014: 114].

М. В. Панов (1920-2001)

* Исследование выполнено при финансовой поддержке РФФИ. Проект «Многоуровневая фонология русского языка», № 15-04-00338. 
0. Эпиграфом к этой статье стало высказывание М.В. Панова, в котором он говорит о своей фонологической теории 1967 г. Несмотря на общую критическую оценку итогов своего труда, М.В. Панов понимал, что предложенное им фонологическое учение содержит потенциал для дальнейшего развития. В 2000-2010 гг. мною была предпринята попытка в ряде работ развить идеи своего учителя [Coколянский 2001; 2007a; 2007b; 2007c; 2007d; 2010]. Если оценить предложенное мною с эстетической точки зрения, как это делает М.В. Панов в отношении своего учения, то следует признать, что и моя теория вряд ли может быть признана красивой, но мне кажется, что какие-то шаги, снимающие некоторые противоречия в теории М.В. Панова, мною были сделаны. Я продолжаю размышлять о проблемах фонологии, поэтому предлагаемый в статье вариант многоуровневой фонологии, скорее всего, еще будет дорабатываться. Надеюсь, что Михаилу Викторовичу мои размышления были бы интересны, хотя я отчетливо знаю, какие из предлагаемых мною решений им были бы отвергнуты.

1. Различные фонологические школы неодинаково определяют единицу, которую называют фонемой. Учение о фонеме сложилось в результате осознания того, что понятие звука является явно недостаточным для описания фонетической системы. Фактически уже само по себе противопоставление «звук фонема» является проявлением многоуровневого подхода в фонетике. Большинство фонологических школ исходит из того, что для них вполне достаточным является названное противопоставление, в основе которого лежит представление о звуке как сегментной единице с определенным набором физических свойств (акустических и артикуляционных) и о фонеме как о сегментной единице, выполняющей различительную функцию. Следовательно, фонема — это совокупность звуков, объединенных различительной функцией. Если бы все фонологи жестко исходили из данного определения, то не существовало бы различных подходов в описании фонемы. Каждая фонологическая школа к этому базовому пониманию добавляет нечто, что приводит к разнообразию фонологических направлений.

Проблема заключается в том, создает ли функция единицу (тогда целесообразнее исходить из многоуровневой фонологии) или приводит к многофункциональности единицы (тогда уместнее моноуровневая фонология). Очевидно, что оба подхода имеют свои издержки. При первом есть опасность рассыпать описание фонетики по разным разделам, которые будут слабо связаны друг с другом. Второй может привести к тому, что разные функции фонемы будут смешиваться в пределах единого анализа, а исследователь не будет замечать, когда фактически переходит от одних свойств фонемы к другим.

Представляется, что сверхзадача многоуровневой фонологии состоит в учете максимально большего количества разных подходов к фонеме в рамках одного описания. При этом многоуровневость может вобрать в себя описание не только собственно фонологических свойств, но и исключительно фонетические аспекты функционирования звуковых единиц. 
В фонеме осуществляется постепенное восхождение от сугубо материальных свойств речевого потока к идеальным свойствам языка. Рождаясь в определенным образом устроенном речевом аппарате, фонема постепенно отрывается от своего анатомического носителя и становится единицей языка, т. е. частью иерархически организованной семиотической системы.

Содержание многоуровневой фонологии состоит в том, что функции фонетических единиц распределяются по разным этажам фонетической структуры, создавая тем самым эти этажи.

2. Язык имеет слоговое строение подобно тому, как живые организмы имеют клеточное строение. Предназначение слога - донести до слухового аппарата участников коммуникации сегментные и суперсегментные параметры рожденного в речевом аппарате звукового потока.

Слог следует рассматривать, скорее всего, не как единицу языка или речи, а как фонетический субстрат, на базе которого функционируют все другие единицы. Поэтому не слог состоит из звуков, а звуки выделяются из состава слога. Слог - это способ организации фонетических единиц. Образно такое понимание было сформулировано Р.К. Потаповой: «Слог как бы маленькая сцена, а действующие на ней персонажи - сила звука, тон, длительность и др.» [Златоустова 1997: 193]. Слог является частью речевого потока, о котором фонетисты часто упоминают, но редко утруждают себя какими-либо определениями, предполагая, что данное понятие ввиду своей очевидности в определении не нуждается. Ближе всего к нашему пониманию речевого потока был Л. Ельмслев, писавший: «Единственно, что дается исследователю языка в качестве исходного пункта... так это текст в своей нерасчлененности и абсолютной целостности» [Ельмслев 1960: 273]. В неявном и синкретичном виде слог выполняет все те функции, которые характерны для других фонетических единиц. «Нерасчлененность» и «абсолютная целостность» - важнейшие свойства речевого потока [Соколянский 2010a, 17-40; Соколянский 2010b].

Отношение фонематических единиц к слогу в разных языках мира не является одинаковым. При обсуждении теории праславянских группофонем В. К. Журавлева с питерскими коллегами было предложено различать следующие типы языков: 1) языки слогофонемного строя, в которых слог совпадает с морфемой (типа китайского, бирманского); 2) языки группофонемного строя, в которых на фонетическом уровне присутствует стремление организовать единицу слогофонемного строя, но препятствием к этому являются морфемные границы, пролегающие внутри группофонемы (таким был праславянский язык на определенном этапе своего развития, см. [Журавлев 2007]); 3) языки фонемного строя. Очевидно, что современный русский язык относится к языкам фонемного строя, с некоторыми «родимыми пятнами» группофонемного языка.

3. Речевой поток представляет собой единство речи и языка. Дальнейшее разграничение единиц многоуровневой фонологии связано с разграничением этих 
фундаментальных для языкознания понятий. Среди единиц многоуровневой фонологии предлагается различать звуки и фонемы.

В настоящее время принято разграничивать звуки речи и звуки языка (П. С. Кузнецов, М.В. Панов, Л. Л. Касаткин) [Кузнецов 1970; Панов 2007; Касаткин 1982], хотя до сих пор введение в научный оборот понятия «звук языка» вызывает споры. В дополнение к этому разделению автором статьи было предложено различать звуки речи первого рода и звуки речи второго рода [Соколянский 2007].

Звук речи первого рода - это звук, произнесенный конкретным говорящим здесь и сейчас. Функция звука речи первого рода состоит в том, чтобы сформировать акустико-артикуляционные свойства, которые без существенных погрешностей могут быть восприняты слушающим. Специфические свойства звуков речи первого рода состоят в их способности дать информацию о состоянии говорящего в момент коммуникации, т.е. здесь и сейчас (настроение, состояние здоровья и др.).

Звук речи второго рода - это типичный для каждого отдельного говорящего способ произнесения звуков. Специфические свойства звуков речи второго рода заключаются в их принципиальной возможности дать информацию о целом ряде постоянных свойств говорящего (отличие от других говорящих, пол, возраст и др.). Это свойство индивидуализирует произношение каждого отдельного говорящего.

«Звук языка - это звуковой тип, эталон звука, существующий в языковом сознании говорящих» [Касаткин 1982: 98-99]. Строго говоря, с традиционной точки зрения звук языка - это оксюморон, так как звук по определению представляет собой явление речи. Тем не менее данный термин очень хорошо раскрывает суть явления. Функция звука языка - установить связь между индивидуальным звуком речи и общепринятыми в данном языковом коллективе звуковыми эталонами языка. Звук языка в отличие от фонемы не выполняет функции различения. Количество звуков языка в практическом плане поддается подсчету (оно коррелирует с числом знаков точной транскрипции), а в теоретическом смысле является бесконечным, так как исследователю не поставлено пределов, где он должен остановиться в процессе выделения всё новых и новых оттенков звуков языка. Несмотря на то что количество звуков языка не поддается исчерпывающему подсчету, нам следует рассматривать его именно как единицу языка, отвечающую за фонетические эталоны. Именно звук языка выполняет перцептивную функцию: звуки речи, воспринимаемые говорящим, соотносятся в его сознании с существующими там звуковыми эталонами, после чего вся поступившая в виде потока речи языковая информация поддается декодированию. По данным, приводимым С.В. Кодзасовым и О.Ф. Кривновой, «в современных автоматических системах синтеза и распознавания речи, которые имеют дело с речевыми реализациями фонем, оказывается необходимым различать более 2000 конкретных оттенков фонем» [Кодзасов, Кривнова 2001: 23]. Проблема с подсчетом звуков языка не должна быть препятствием для понимания его именно как особой единицы языка. Морфемы и слова также с трудом поддаются каталогизации, что не мешает нам рассматривать их как полноценные языковые единицы. 
Различие функций звуков речи и языка можно пояснить на таком детективном примере. Некто спасается от преследователей, подбегает к закрытой двери квартиры, стучит, слышит вопрос: «Кто там?». Отвечает: «Откройте!» [аткро́йт’и]. Какую информацию может извлечь хозяин квартиры из услышанного?

На уровне звука речи первого рода: находящийся за дверью испуган, он долго бежал и др. (изменяемые признаки речи говорящего).

На уровне звука речи второго рода: находящийся за дверью известен / неизвестен хозяину квартиру, это мужчина / женщина / ребенок, это человек молодой / пожилой, это иностранец / русский и др. (постоянные признаки речи говорящего).

На уровне звука языка: находящийся за дверью просит открыть дверь (языковые признаки, устанавливающие общее между слушающим и говорящим), эта информация становится доступной слушающему в результате установления связи между звуками языка и фонематическими единицами.

4. Описанное противопоставление звуков речи и звуков языка представляет собой первые этажи фонематического описания, но не является само по себе основанием для фонологии. Фонологи самых разных направлений давно уже исходят из того, что звуки речи и языка могут быть вычленены только в результате их сопоставления с фонемой. Иначе говоря, не фонема складывается из отдельных звуков, а отдельные звуки вычленяются как результат реализации фонемы. Совсем коротко: фонема первична по отношению к звуку.

В связи с этим актуальной становится проблема сегментации фонемных единиц. Здесь можно взять на вооружение теоретические разработки представителей Ленинградской фонологической школы (ЛФШ), которые кладут в основание этой процедуры морфологический критерий, понимаемый ими иначе, чем это делают московские фонологи. Слово стена состоит из двух слогов - сте-на - и двух морфем - стен/a. Элемент $н$ при слоговом членении отделен от отрезка $c m e$, а во втором случае он является частью корня. Способность элемента оказываться «зажатым» между морфемной и слоговой границей свидетельствует о его фонематической отдельности. Честь открытия данного критерия принадлежит М.В. Гординой [устное сообщение питерских коллег]. В нашем случае это выглядит как cme-н/a. По аналогии элемент $н$ следует рассматривать как особую фонему и в других случаях, включая те, где он не может быть «зажатым» между морфемной и слоговой границей (например нога). Думается, что наработки петербургских фонологов в области вычленения фонемных единиц могут быть приняты на вооружение и другими фонологическими школами.

Можно ли петербургскую фонему рассмотреть в качестве одного из этажей многоуровневой фонологии? Вероятно, можно. Но на этом пути возникают определенные сложности. Сложилось весьма устойчивое мнение, что петербургская фонема - звукотип, т. е. в одну фонему объединяются звуки, обладающие определенным материальным сходством. Именно это материальное сходство позволяет говорящим на уровне осознания этих единиц объединять их в единства - в фонемы. Сегодня некоторые петербургские фонологи категорически не принимают 
такую интерпретацию собственной фонологической школы, настаивая на том, что звуки объединяются в фонемы не на основе физического тождества, а исключительно на основании осознания их говорящими. Такой подход - это возврат к истокам фонологии, когда фонема понималась как психический эквивалент звука, см. [Соколянский 2016: 89-93]. Психофонему крайне трудно включить в многоуровневую фонологию, которая своим истоком имеет Московскую фонологическую школу (МФШ), активно отвергающую психологический подход к явлениям языка и, в частности, к объектам фонологии. В то же время петербургская фонема как звукотип могла бы быть рассмотрена в качестве одного из уровней многоуровневой фонологии.

В таком случае она должна быть сопоставлена со звуком языка. Отличие звука языка от ленинградской фонемы состоит в том, что звук языка не выполняет смыслоразличительную функцию, а только перцептивную, см. [Полковникова 1998; Князев 2007], тогда как ленинградская фонема - смыслоразличитель. Просто говоря, произносительные сегменты [á - ·á - á· — á - ã] являются разными звуками языка, но представляют собой одну ленинградскую фонему, так как по отношению друг к другу не могут выполнять смыслоразличительную функцию.

От звука языка лежит прямой путь не только к ленинградской фонеме. Фонема - это звук языка, наделенный различительной функцией. Наделяя звук языка этой функцией, мы тем самым превращаем его в фонематическую, т. е. языковую единицу.

5. В процессе анализа фонематических единиц следует учитывать то, что В.К. Журавлевым когда-то было названо «силой фонологической оппозиции» [Журавлев 1974: 59]. В наших работах был использован термин «коэффициент различительной силы», который учитывает количество единиц, противопоставленных в той или иной позиции. Так, коэффициенты различительной силы в слове [тот] распределяются как $/ \mathrm{T}_{37} \mathrm{O}_{5} \mathrm{~T}_{21} /$, что означает: перед гласной противопоставлено 37 согласных, в ударной позиции после твердого согласного противопоставлено 5 гласных, на конце слова различается 21 согласный. Единица, выделяемая только на основе различительных свойств звука языка, может быть названа дифференииаmор. Это своеобразная предфонема, или протофонема, которая по многим параметрам могла бы претендовать на звание собственно фонемы. Можно предложить такое определение: дифференцииатор - это звук языка в аспекте выполнения им различительной функиии.

Дифференциитор = звук языка + различительная функичя

Предназначение дифференциатора - отличаться от других дифференциаторов. Ни одна фонологическая школа не использует понятие дифференциатора в том виде, как оно только что было сформулировано, но все они имплицитно отталкиваются от него, формулируя свое понимание фонемы.

Дифференциатор жестко привязан к той позиции, в которой он выделяется. Так, в позиции между твердыми согласными под ударением возможно функционирование пяти дифференциаторов: [пат — пер 'пэр' — пот — пыл — пуп] 
$=/ \mathrm{a}-\mathrm{e}-\mathrm{o}-\mathrm{d}-\mathrm{y} /$. Дифференциатор /a/ мы можем охарактеризовать как звук языка [а], находящийся в позиции, в которой противопоставлены 5 единиц. В позиции между мягкими согласными также представлено 5 единиц: [п'ӓт' — п'е̂т' т'ӧт'ъ - п'ит' - кл'ӱч']. Оставаясь в рамках параметров, заданных для дифференциатора, мы не можем осуществить попарное отождествление [a - ä], [e - ê], [o - ӧ], [ы - и], [у - ӱ]. Различие звуков языка не позволяет признать эти пары в качестве одной единицы. Одинаковый коэффициент различительной силы (равный в обоих случаях 5) - важное, но недостаточное основание для их объединения. Анализ дифференциаторов дает разделенное по позициям описание фонетики, именно поэтому фонологи не всегда считают необходимым давать описание количества единиц, противопоставленных в каждой позиции.

В свое время автор этих строк рассматривал дифференциатор как отдельную единицу, но описание получилось крайне громоздким. В конечном итоге пришлось прийти к выводу, что полный перечень дифференциаторов можно построить для гласных, но процедура превращается в дурную бесконечность при попытке описать систему консонантизма. Поэтому сегодня автор статьи определил бы дифференциатор не как единицу, а как основополагающий критерий при выделении фонологических единиц.

Различные фонологические школы на основе дифференциатора формируют свое собственное представление о фонеме, дополняя дифференциатор свойствами, которые каждая отдельная школа считает важными для фонемы. Такой подход можно представить в виде формулы: фонема $=$ дифференциатор + специифический подход фонологической школь.

6. На примере фонологических школ, сложившихся в России, это схематически можно представить следующим образом:

ЛФШ: фонема = дифференциатор + осознание говорящими.

ПФШ: фонема = дифференциатор + единство дифференциальных признаков.

МФШ: фонема = дифференциатор + снятие позиционных различий.

6.1. Ленинградская фонологическая школа устанавливает прямую связь между фонемой и значимыми единицами языка. Эта связь состоит в способности фонемы непосредственным образом обозначать морфему. Например, в слове скакалка звук [c] может обозначать приставку или предлог (сломать, $\underline{\boldsymbol{c}}$ мамой), [к] — предлог (ㄸ акуле), [a] - окончание (стена) и др. У некоторых фонем связь со значимыми единицами строится по аналогии. Так, [п] в русском языке не обозначает отдельной морфемы, но находится в одном ряду с единицами, которые этим свойством обладают. Следовательно, [п] имеет потенциальную связь со значимыми единицами языка, т. е. при наличии определенных условий мог бы обозначать морфему.

При таком подходе ЛФШ не считает необходимым разграничивать сильные и слабые фонологические позиции, отождествляя начальный и конечный звук в слове [поп] на основе осознания их близости говорящими. Фонемный состав слова /поп/. «Тем самым, хотя представители ЩФШ (= ЛФШ. - A. C.) и используют 
термины сильная и слабая позищия, в частности, когда речь идет о чередованиях фонем в морфеме, для этой школы понятия, обозначенные соответствующими терминами, не являются принципиально важными при определении фонемного состава словоформы» [Попов 2014: 264-265].

Представители ЛФШ возражают против того, что в полемике с ними «москвичи» часто утверждают, что «ленинградская» фонема выявляется на основе физического подобия. Так, М.Б. Попов пишет: «...представители ЩФШ делают его, исходя из языкового сознания носителей языка, но ни в коем случае не из критерия артикуляторно-акустической близости соответствующих звуков...» [Попов 2014: 264]. С точки зрения МФШ, в фонологии два основных греха: физикализм и психологизм. Бо́льшим грехом считается психологизм. Поэтому, полемизируя с питерскими коллегами, московские фонологи деликатно упрекают их в меньшем грехе. По крайней мере с их, московской, точки зрения.

Стало быть, с точки зрения ЛФШ, фонема - это совокупность дифференциаторов, имеющих непосредственную связь со значимыми единицами языка и осознаваемых говорящими в качестве эквивалентных. Из свойств дифференциатора ЛФШ интересует только сам факт противопоставленности другим единицам, тогда как количество противопоставленных единиц при принятии фонологических решений не имеет значения.

Объединение звуков типа [a - ä], [e - ê] и др. осуществляется на основании их близости в сознании говорящих. Вместе с тем опора на сознание говорящих в целом и в данном случае может дать весьма неоднозначную картину. Так, носители языка, не обремененные фонологическими премудростями, скорее всего, не заметят различий в произношении [e] в словах шест и тесто, однако очень часто автору этих строк приходилось сталкиваться с людьми, которые были убеждены, что в словах маска и мясо они произносят разные звуки. Строго говоря, они правы: здесь разные звуки, но одна фонема. В таких случаях приходится прибегать к дополнительным приемам. Например, предлагать протянуть в произношении гласный [·a], с тем чтобы убедиться в том, что в таком случае он переходит в [а]. Прием не безупречный.

Можно ли в многоуровневой фонологии выделить уровень описания, соответствующий фонеме ЛФШ? Такое построение вполне возможно. Такую единицу можно было бы назвать первичной фонемой.

6.2. Пражская фонологическая школа (ПФШ) пошла по пути выделения в структуре фонемы признаков, которые позволяют одной фонеме отличаться от другой. Это привело к построению теории оппозиций и производному от нее учению о нейтрализации. Фонема - дифференциатор, обладающий одинаковым набором различительных признаков. В слове поn фонемный состав /поП/. В позиции нейтрализации на конце слова представлена архифонема /П/, имеющая на один дифференциальный признак меньше фонемы /п/, находящейся в позиции перед гласным.

6.3. Московская фонологическая школа также в основу понимания фонемы кладет дифференциатор. Дифференциаторы разных позиций объединяются в одну 
фонему на основе позиционного подхода. Фонема - это ряд дифференциаторов, позиционно чередующихся в пределах морфемы (точнее - морфа). При таком подходе нагляднее всего решается вопрос об объединении дифференциаторов в разных позициях. В слове поп конечный согласный относится к фонеме $<$ п>, так как в пределах морфемы чередуется с [п] (non - nonbl), а в слове бon - к фонеме $<\sigma>$, так как в пределах морфемы чередуется с [б] (бo[п] - бо[б]bl). Правда, на этом пути МФШ сталкивается с проблемой единиц, которые не могут находиться в сильной позиции. Разрешение этой проблемы привело к учению о гиперфонеме, т. е. фонеме, которая не может находиться в сильной позиции ( $\left.c[\mathrm{a}] б а к а,\left[3^{\prime}\right] e c\left[\mathrm{c}^{\prime}\right]\right)$.

7. Включение в определение фонемы связи со значимыми единицами в конечном итоге привело московских фонологов к необходимости наряду с различительной функцией фонемы говорить о функции отождествления. По отношению к другим фонологическим единицам фонема выполняет функцию различения, а по отношению к значимым единицам - функцию отождествления. В слове вódbl фонема $<$ o $>$, выполняя функцию различения, противопоставлена фонемам $<\mathrm{a}-$ e - и - y> и, выполняя функцию отождествления, идентифицирует морфему вод

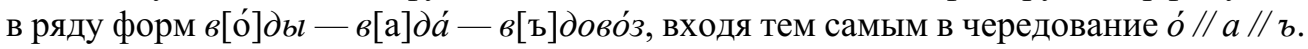

Проблему соотношения двух функций фонологических единиц МФШ решала тремя путями: 1) создание многоуровневой фонологии, в которой каждая функция закреплена за особой единицей (С.И. Бернштейн [Бернштейн 1962], «поздний» Р. И. Аванесов [Аванесов 1956], «ранний» М.В. Панов [Панов 1967]); 2) отказ от одной из функций фонемы, а именно функции различения («поздний» М.В. Панов [Панов 1979]); 3) признание за фонемой двух функций (К. В. Горшкова [Горшкова 1980], Л.Л. Касаткин [Касаткин 2009]).

Р.И. Аванесов [Аванесов 1956] предложил различать сильные и слабые фонемы, которые в свою очередь объединялись в фонемные ряды. Разграничение сильных и слабых фонем по сути вводило иерархические отношения между фонемой / вариацией и вариантом: на первом уровне членения языковой системы различались единицы, обладающие максимальной различимостью, на других уровнях - единицы с ослабленной функцией различения. В слове трава два [а] относятся к разным фонемам (так как первый [а] (у Р. И. Аванесова [ᄉ]) противопоставлен меньшему количеству единиц, чем [а] под ударением), но при этом входят в один фонемный ряд.

М.В. Панов [Панов 1967] наиболее последовательно с позиций МФШ произвел разграничение двух функций фонемы. Функцию различения он определил за синтагмо-фонемой, функцию отождествления за парадигмо-фонемой. Позднее Л. Л. Касаткин [Касаткин 2009], выступая против такого разграничения, настаивал на том, что в данном случае мы имеем дело не с двумя единицами, а с различными функциями одной единицы. В своих решениях Л. Л. Касаткин основывался на работах К.В. Горшковой. Таким образом, можно сказать, что эволюция многоуровневой фонологии привела в конечном итоге к идее многофункциональности фонемы, рассматриваемой в пределах моноуровневой фонологии. 
Не исключая возможности различных фонологических моделей в описании звуковой системы русского языка, автор этих строк является сторонником многоуровневой фонологии, так как считает, что именно такой подход позволяет более четко определить функциональные свойства звуковых единиц. Предлагаемую модель фонологического описания можно представить в следующем виде.

8. Дифференцииатор - звук языка, рассматриваемый в аспекте различительной функции. Особенности дифференциатора: 1) связь только с одной позицией; 2) практическая сложность в выявлении количества дифференциаторов.

Первая особенность была описана нами ранее, на второй кратко остановимся сейчас.

По умолчанию принято считать, что для согласных интервокальная позиция и позиция начала слова являются тождественными. Иначе говоря, в словах $\underline{c} a \partial$ и пос $\underline{a \partial \kappa a ~ с е г м е н т ~[с] ~ н а х о д и т с я ~ в ~ о д н о и ̆ ~ и ~ т о и ̆ ~ ж е ~ п о з и ц и и . ~ Э т о ~ п о л о ж е н и е ~ в о ~ м н о-~}$ гом верно для сочетаний \#СГ и ГСГ (\# - знак начала слова, С - согласный, Г гласный), однако и здесь можно обнаружить различия. Так, из долгих смычных в начале слова могут употребляться только заднеязычные: к кому, к киту, к городу и др. Русский язык не знает долгих [п- п' - б - б' - т - т' - д - д' — ц — ч’] в начале слова. Ограничение распространяется и на такие смычные, как [м - м' н - н' — л — л'] (сомнительно, что в редких словах типа Ллойд Джордж мы произносим долгий [л], см. [Соколянский 2013]).

Значительно больше отличий в количестве дифференциаторов можно обнаружить при анализе сочетаний \#ССГ и ГССГ. Наиболее разительную картину представляет /j/, который встречается практически перед всеми согласными в последовательности ГСС Г (тайга, зайка, война и т. п.) и вообще не встречается в позиции \#ССГ.

В других случаях различия не столь заметны, но также весьма существенны. В начале слова перед сочетанием $p / p^{\prime}+\Gamma$ возможно употребление 16 согласных: брат, врать, грань, драть, жрать, зрачок, краб, мрак, нрав, правда, срам, трость, фраза, храп, шрам, чрево. В интервокальной позиции их число может доходить до 22: образ, овраг, награда, вылдра, пожрать, возраст, сайра, окраина, помрачение, жанровый, оправа, террор, досрочный, отрава, шафран, махровый, ГОЭЛРО, кольраби, шпицрутен, спичрайтер, поощрять, маршрут. Отличие в коэффициенте различительной силы требует считать согласные [б] в словах брат и образ разными дифференциаторами.

Количество дифференциаторов в биконсонантных сочетаниях с трудом поддается подсчету, тем не менее выявление дифференциальных свойств фонологических единиц необходимо. Предлагается рассматривать дифференциатор не как отдельную языковую единицу, а как один из параметров, который следует принимать во внимание при фонологическом анализе.

9. Синтагмо-фонема - фонологическая единица, выполняющая функцию различения и характеризующаяся как совокупность одинаковых дифференциальнblx признаков. Данная единица соотносится с фонемой ПФШ. Признак является 
основным параметром синтагмо-фонемы. Традиционная фонетика основное внимание уделяла изучению признаков отдельных звуков. Общность признаков звуков языка была основой для их классификации. Фонология рассматривает уже выделенные в фонетике признаки с точки зрения выполнения ими различительной функции. Теоретическое обоснование формирование фонологических признаков на базе фонетических получило в работах Н. С. Трубецкого [Трубецкой 1960: 101].

Количество фонетических признаков в принципе не является ограниченным, тогда как число различительных признаков должно быть строго определенно. Первый этап фонологии был связан с разделением всех признаков на дифференциальные и недифференциальные. Так, признак глухости / звонкости был отнесен к дифференциальным, а признак напряженности/ненапряженности к недифференциальным. Особое положение заняли интегральные признаки - дифференциальные для системы в целом, но не выполняющие функции различения в структуре конкретной синтагмо-фонемы (например признак глухости у/ц/).

10. Следует определить, в какой степени фонетическая классификация звуков отвечает требованиям фонологии. На пути трансформации фонетической классификации в фонематическую у нас три основных резерва:

1) иерархизация имеющихся фонетических признаков;

2) устранение избыточности фонетической классификации с точки зрения функции различения;

3) устранение по мере возможности многоступенчатости классификаций звуков языка.

10.1. Устранение недифференциальных признаков из фонологической классификации усиливает разрыв между фонетикой и фонологией. Поэтому более продуктивен путь установления иерархии между дифференциальными и недифференциальными признаками. Возглавляет эту зависимость дифференциальный признак. Тогда фонологический признак глухости / звонкости можно представить в виде такой иерархии: глухость / звонкость $\subset$ напряженность / ненапряженность $\subset$ долгота / краткость $\subset$ придыхательность / непридыхательность. Знак $\subset$ обозначает 'влечет за собой'. В работы по фонологии его ввел М.В. Панов [Панов 1967: 155]. Поэтому, обозначая фонологический признак, к примеру, синтагмо-фонемы /т/ как глухой, мы имеем в виду не только отсутствие вибрации голосовых связок, но и всю совокупность связанных признаков, которые могут в зависимости от позиции и конкретных произносительных условий реализовывать себя различным способом. Таким образом почти всё содержание фонетики может войти в состав фонологии [Соколянский 2016].

10.2. В основе описания синтагмо-фонемы лежит характеристика звука языка, но при этом между этими двумя характеристиками существуют значительные различия. При описании звука языка мы выделяем в нем максимальное количество признаков: чем больше признаков и чем подробнее описание, тем лучше. При 
описании признаков фонемы наше основное внимание сосредоточено на тех признаках, которые помогают отличать данную фонему от других. Поэтому в процессе фонологического описания следует по мере возможности избегать избыточности фонетической классификации. Представим себе, что оппозиция губно-губных и губно-зубных в русском языке фонематична. Тогда у нас должны быть противопоставлены фонемы: /П/ — губно-губная и / ${ }^{\Phi} /$ — губно-зубная, но звук $\left[\Pi^{\phi}\right]$ вообще встречается крайне редко. В русской фонетике могут быть противопоставлены губно-губной [м] и губно-зубной [m]. Последний в русском произношении может встретиться (необязательно!) в словах типа амфора. Опять-таки такая фонемная пара в русском языке отсутствует. Теоретически в русском языке могло бы быть противопоставление /в/ и /w/ (как в английском языке), но русский язык не знает их употребления в рамках одной системы (нельзя исключать, что в говорах переходного типа нечто подобное наблюдается).

Наверное, можно вывести формулу преобразования фонетических признаков в фонематические: если нет противопоставления $[\mathrm{M}] \div[\mathrm{m}],[\mathrm{w}] \div[\mathrm{B}],[\varphi] \div[\phi]$, $[\Pi] \div\left[\Pi^{\phi}\right],[б] \div\left[\sigma^{в}\right]$ в одной позиции, то фонетические признаки губно-губной $\times$ губно-зубной должны рассматриваться как реализация фонемного признака губной.

10.3. Характеристики согласных по месту и способу образования являются многоступенчатыми. Для фонологии это представляет определенное неудобство, поэтому по мере возможности следует многоступенчатые классификации преобразовывать в одноступенчатые. Практически так поступают все фонологии, работающие с фонемными признаками. Поэтому, к примеру, классификация по месту образования предусматривает разделение согласных по следующим признакам: губные - зубные - альвеолярные - среднеязычные - заднеязычные.

11. В некоторых позициях происходит утрата количества противопоставленных фонологических единиц. Такие позиции называются позициями нейтрализации. В позиции нейтрализации структура дифференциальных признаков иная. Здесь можно выделить два случая:

1) в позиции нейтрализации происходит утрата количества дифференциальных признаков;

2) в позиции нейтрализации происходит сокращение структуры строения самого дифференциального признака.

11.1. В позиции конца слова отсутствует класс звонких согласных, следовательно, фонемная характеристика становится короче на один признак. Единица, имеющая более короткую функциональную характеристику, является архифонемой: /т/ $\times / д / \rightarrow /$ /. Синтагмо-фонема /T/ имеет характеристику, включающую в себя четыре признака: зубная (в отличие от /П/, /к/), взрывная (в отличие от /с/), твердая (в отличие от /T'/), глухая (в отличие от /д/). Архифонема /T/ имеет сокращенную признаковую характеристику, включающую три признака, так как на конце слова глухие и звонкие не противопоставлены. 
11.2. Другая разновидность нейтрализации связана с упрощением строения дифференциального признака. Дифференциальный признак фрикативных согласных имеет пятичленную структуру: губной /ф/ — зубной /с/ — альвеолярный /ш/ среднеязычный /j/ - заднеязычный /x/. В позиции перед шипящими происходит утрата противопоставления /c/ и /ш/ (с шилом [шшы́лъм]). В данном случае можно говорить о преобразовании признака в архипризнак: зубной $\times$ альвеолярный $\rightarrow$ ПЕРЕДНЕЯЗЫЧНЫЙ. Пятичленная структура признака преобразуется в четырехчленную. Такие случаи следует рассматривать тоже как разновидность нейтрализации [Соколянский 2016b].

12. Выявленную в синтагмо-фонологии признаковую структуру можно наложить на отношения в системе дифференциаторов. В позициях \#ССГ и ГССГ перед / $\mathrm{p} /$ синтагмо-фонема /T/ (трость, отрава) характеризуется одним и тем же набором дифференциальных признаков: зубная (в отличие от /п/, /к/ (прав$\partial а$, оправа)), взрывная (в отличие от /с/ (срам, досрочный)), глухая (в отличие от /д/ (драть, выдра)). Противопоставление по твердости / мягкости в этой позиции представлено только у пары /л/ — /л'/ (ГОЭЛРО, кольраби). Следовательно, звук [т] в этой позиции является архифонемой $/ \mathrm{T} /$, характеризующейся тремя признаками. Для дифференциатора главное - количество противопоставленных единиц, поэтому два [т] в начале слова и в интервальной позиции должны быть отнесены к разным дифференциаторам. Для синтагмо-фонемы главное - набор дифференциальных признаков, поэтому два [т] в данном случае являются одной и той же архифонемой.

Архифонема - это один из способов реализации синтагмо-фонемы. Следовательно, синтагмо-фонемы могут быть представлены в виде собственно синтагмофонем и архифонем. Каково соотношение между ними? Можно ли рассматривать архифонему как альтернат синтагмо-фонемы, т. е. рассматривать их соотношение в виде $/ \mathrm{T} /=/ \mathrm{T} / \| / \mathrm{T} /$ ? М.В. Панов соотношение синтагмо-фонем с разным объемом дифференциальных признаков не решился рассматривать как чередование. Он писал о том, что эти единицы находятся в соответствии [Панов 1967: 106].

Архифонема функционирует в позиции нейтрализации. Нейтрализация - это снятие противопоставления между единицами в определенной позиции. Это явление различно понимается в фонологии. Нейтрализацию по-московски можно назвать позиционно-морфемной, она включает в себя четыре основания: 1) определяется фонетической позицией (в отличие от морфонологических явлений); 2) приводит к уменьшению количества противопоставленных единиц; 3) приводит к упрощению признаковой структуры фонемной единицы, т.е. к появлению архифонемы; 4) осуществляется в пределах одной морфемы. Нейтрализацию по-пражски можно назвать позиционно-словесной: она обладает первыми тремя свойствами, но безразлична к четвертому требованию. Для ПФШ проявление нейтрализации в морфеме, скорее, вопрос наглядности, чем теоретических оснований. Сопоставление $\partial y \underline{\boldsymbol{\sigma}} b \dot{l}-\partial y \underline{\boldsymbol{n}}$ нагляднее, чем $\partial y \underline{\boldsymbol{\sigma}} b \dot{l}-\kappa л о \underline{\boldsymbol{n}}$, но для ПФШ в принципе эти примеры равноправны. 
С точки зрения МФШ, чередование происходит в определенных позициях и определенных морфемах. С точки зрения ПФШ, достаточно ограничиться разными позициями. Всё дело в том, что МФШ не считает непременным условием фонематического анализа выявление признаковой структуры фонемы, для объединения звуков в одну фонему вполне достаточно того, что они позиционно чередуются в пределах морфемы. Напротив, для ПФШ нахождение в одной морфеме не является непременным условием объединения в одну фонему. Главным является признаковая структура.

13. Чередование может приводить к ослаблению функции синтагмо-фонемы. Традиционно различают чередования, не приводящие к нейтрализации (параллельные), и чередования, приводящие к нейтрализации (перекрещивающиеся).

На примере гласных /a/ и /о/ это может быть представлено следующим образом:

$\begin{array}{ccc}\begin{array}{l}\text { Ударная позиция } \\ / \mathrm{a} /=\{\mathrm{a} / / \mathrm{a} \cdot / / \cdot \mathrm{a} / / \mathrm{a}\}\end{array} & \text { Безударная позиция после твердых } & \text { Безударная позиция пос } \\ / \mathrm{o} /=\{\mathrm{o} / / \mathrm{o} \cdot / / \cdot \mathrm{o} / / \mathrm{o}\} & \left\{\mathrm{a}^{\mathrm{b}} / / \mathrm{a}^{\mathrm{b} \cdot / / \mathrm{b}}\right\} & \\ / \mathrm{e} /=\{\mathrm{e} / / \mathrm{e} \cdot / / \cdot \mathrm{e} / / \hat{\mathrm{e}}\} & & \\ / \mathrm{u} /=\{\mathrm{u} / / \mathrm{u} \cdot / / \mathrm{u}\} \\ / \mathrm{y} /=\{\mathrm{y} / / \mathrm{y} \cdot / / \cdot \mathrm{y} / / \ddot{\mathrm{y}}\} & \left\{\mathrm{e}^{\mathrm{b}} / / \mathrm{e}^{\mathrm{b}} \cdot / / \mathrm{e}^{\mathrm{b}}\right\} & \\ & \{\mathrm{d} / / \mathrm{d} \cdot / / \mathrm{b}\} & \{\mathrm{y} / / \ddot{\mathrm{y}}\}^{1}\end{array}$

Схема отражает икающий тип произношения и присутствие в системе после твердых согласных в безударном положении /e/. В рассмотренных нами случаях можно констатировать чередование синтагмо-фонем и архифонем:

$$
\begin{aligned}
& / \mathrm{a} /=\mathrm{a} / / \mathrm{A} / / И \\
& / \mathrm{o} /=\mathrm{o} / / \mathrm{A} / / И \\
& / \mathrm{e} /=\mathrm{e} / / \mathrm{e} / / И \\
& / \mathrm{u} /=\mathrm{и} / / \text { и } / / И \\
& / \mathrm{y} /=\mathrm{y} / / \mathrm{y} / / \mathrm{y} .
\end{aligned}
$$

14. Связь между этими альтернантами осуществляется через позицию, а не морфему. Иначе говоря, соотношение травы - трава, дров - дрова является только наглядным способом продемонстрировать нейтрализацию $a \times o \rightarrow A$. В принципе синтагмо-фонология может обойтись и без этого. На самом деле мы имеем соотношение ударной позиции, в которой различается пять единиц $/ \mathrm{a}-\mathrm{o}-\mathrm{e}-\mathrm{u}-\mathrm{y} /=$ [á - ó - é - b́ - ý], и предударной, в которой различается четыре единицы /А $\mathrm{e}-\mathrm{u}-\mathrm{y} /=\left[\mathrm{a}^{\mathrm{b}}-\mathrm{e}^{\mathrm{b}}-\mathrm{d}-\mathrm{y}\right]$. Все фонологические школы исходят из того, что слабые позиции содержат те же единицы, что и сильные, но только с учетом изменений, вызванных влиянием позиции. А. А. Реформатский специально оговаривал,

\footnotetext{
${ }^{1}$ Фигурные скобки \{\} выполняют функцию объединения единиц, имеющих одинаковую различительную силу.
} 
что состав фонем языка определяется по сильным позициям. На уровне звуков языка устанавливаем соответствие между [á - $\left.\mathrm{a}^{\mathrm{b}}\right]-\left[\mathrm{e}-\mathrm{e}^{\mathrm{b}}\right]-\left[\mathbf{b}^{\prime}-\mathrm{b}\right]-[\mathrm{y}-\mathrm{y}]$. Вне соответствия остается ударный [ó], который по своей признаковой структуре связан с [á].

/о/ - слабо лабиализованный, среднего подъема

/a/ - нелабиализованный (нижнего подъема).

В безударной позиции слабая лабиализация утрачивается, в результате чего происходит нейтрализация $a \times o \rightarrow A$, сопровождаемая преобразованием градуального дифференциального признака в привативный: /лабиализованный - слабо лабиализованный - нелабиализованный/ $\rightarrow$ /лабиализованный - НЕЛАБИАЛИЗОВАННЫЙ/, т.е. $y \times(a \times o) \rightarrow y \times A$. Возможность использовать морфологический критерий при установлении соответствия между единицами в разных пози-

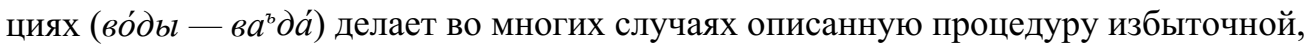
но теоретически именно она для синтагмо-фонологии является корректной.

Иногда соответствия между единицами не могут быть установлены с помощью морфологического критерия. В уже рассмотренной позиции функционирования согласных в позиции перед сочетанием /p $/$ / все согласные (кроме [л’]) не противопоставлены по твердости/мягкости, т. е. представляют собой архифонему, их соответствие синтагмо-фонеме в сильной позиции может быть установлено только через анализ признаковой структуры (ПФШ) или с помощью установления соответствия на уровне звуков языка (ЛФШ).

Для каждой позиции фонематические свойства единиц должны определяться отдельно, а потом согласовываться друг с другом.

15. Парадигмо-фонема - фонологическая единица, выполняющая функцию отождествления значимых единиц и реализующаяся в виде позиционно чередуюшиихся звуков языка.

Иногда раздаются призывы к МФШ отказаться от парадигмо-фонемы и объявить настоящей только синтагмо-фонему [Осипов 2016]. Сами же представители МФШ скорее склонны отказаться от синтагмо-фонемы, справедливо при этом считая, что отказ от парадигмо-фонемы приведет к разрушению основ школы. МФШ видит свое главное достижение в том, что ей удалось «подняться» над материей и объединить в одну фонематическую единицу звуки только на основе того, что они позиционно чередуются.

Остановимся на наиболее болезненном вопросе, который возникает в связи с московской парадигмо-фонемой: можно ли выделение звуковой единицы ставить в зависимость от значимых единиц языка?

Данный вопрос принадлежит к числу вопросов, находящихся на грани аксиоматики. МФШ считает, что фонетика - это часть языковой системы, поэтому ее изучение вне связи с другими уровнями будет носить ущербный характер.

Претендентов на соотношение с парадигмо-фонемой может быть несколько: морф, морфема, словоформа. Очевидно, что парадигмо-фонема соотносится с морфом. Возьмем ряд однокоренных слов: ногу, нога, ног, ножной 
[но́гу — на ${ }^{\mathrm{b}}$ га́ - нок - на жно́й]. Корневая морфема представлена в виде но́ $=$ $н a^{b} 2=н о \kappa=н a^{b} ж$, которые на морфемном уровне представляют собой тождество. Чередования, которые не препятствуют, а способствуют установлению тождества:

ó // a : [но́гу — на $\mathrm{b}^{\mathrm{b}}$ ѓ $]$

г // к: [но́гу - нок]

г // ж: [нара́ - на'жно́й $]$.

Понятно, что здесь мы имеем чередования разного порядка. Первое и второе обусловлено фонетическими факторами (безударность и конец слова), третье грамматическими (положение перед суффиксом $\mu$ ).

Функция этих чередований - не препятствовать отождествлению значимых единиц: морфов и морфем. Различие между фонетическими чередованиями и грамматическими состоит в том, что члены фонетического чередования не могут встречаться в одной позиции, т. е. выступать по отношению друг к другу как разные синтагмо-фонемы или дифференциаторы. Действительно, архифонема /К/ не может оказаться в одной позиции с синтагмо-фонемой /к/: противопоставление типа */нАга́ - наКа́/ в принципе невозможно. Иная ситуация с грамматическими чередованиями: синтагмо-фонемы /г/ и /ж/ могут оказаться в одной позиции: гать - жать, гора -жара, гарь -жарь, гадина -жадина.

Члены фонетического чередования «помнят» функцию различения, члены грамматического чередования вне этой функции. С учетом разного понимания чередований определение парадигмо-фонемы принимает такой вид: парадигмофонема - это фонологическая единица, выполняющая функцию отождествления морфов и реализующаяся в виде единии, которые не могут по отношению к друг другу выполнять функиию различения.

Рассмотрим в аспекте сказанного пример М. В. Панова, дополнив его признаковой структурой входящих в чередование единиц [Панов 1979: 106-107]:

с Аней — произносится [c], синтагмо-фонема /c/ - 4-признаковая (зубная, щелевая, твердая, глухая);

с Колей — произносится [c], архифонема /C/ - 3-признаковая (зубная, щелевая, твердая 'каска — моська');

с Тимошей - [c'], архифонема /C/ - 2-признаковая (зубная, щелевая);

с Галей — [3], архифонема /C/ - 2-признаковая (зубная, щелевая);

с Димой - [3'], архифонема /C/ - 2-признаковая (зубная, щелевая);

с Шурой — [ш], т. е. [шшу́ръи], архифонема /C/ - 2-признаковая (ПЕРЕДНЕЯЗЫЧНАЯ, щелевая);

с Женей — [ж], т.е. [жже́н'ий], архифонема /C/ - 2-признаковая (ПЕРЕДНЕЯЗЫЧНАЯ, щелевая);

с Чуком - [ш'], т. е. [ш'ч'у́към], архифонема /C/ - 2-признаковая (ПЕРЕДНЕЯЗЫЧНАЯ, щелевая); 
с Чбановым - [ж'], т.е. [ж'д’ж’ба́нъвъм], архифонема /C/ - 2-признаковая (ПЕРЕДНЕЯЗЫЧНАЯ, щелевая);

с Щукарем - $[-]^{2}$.

В этих примерах фонема $<c>$ реализуется рядом позиционно чередующихся звуков языка:

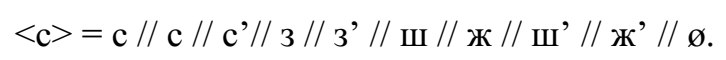

Если представить данный ряд с учетом фонематических свойств чередующихся единиц, то он будет выглядеть так:

$$
\begin{aligned}
& <\mathrm{c}>= \\
& \mathrm{c}=/ \mathrm{c}^{4} / \\
& \mathrm{c}=/ \mathrm{C}^{3} / \\
& \mathrm{c}^{\prime} / / \mathbf{3} / / \mathrm{3}^{\prime}=/ \mathrm{C}^{2} / \\
& \text { ш// ж// ш'// ж'=/C"I/ } \emptyset \varnothing=?
\end{aligned}
$$

Устраняя из этой схемы реализации в виде звуков языка, получаем систему, в которой парадигмо-фонема представляет собой ряд чередующихся синтагмофонем:

$$
<\mathrm{c}>=/ \mathrm{c}^{4} /\left\|/ \mathrm{C}^{3} /\right\| / \mathrm{C}^{2} /\left\|/ \mathrm{C}^{\mathrm{II}} /\right\| ?
$$

Таким образом, парадигмо-фонема может быть представлена как рядом звуков языка, так и рядом синтагмо-фонем. Думается, что оба представления должны дополнять друг друга. Звуки языка точно указывают на фонетическую реализацию парадигмо-фонемы, а синтагмо-фонемы определяют фонологическое содержание реализаций парадигмо-фонемы в каждой отдельной позиции.

16. В систему многоуровневой фонологии должна быть инкорпорирована и морфонология. Центральной единицей морфонологии является морфонема. Морфонема - это единица языка, служащая как средство отождествления морфем, как средство для вспомогательного выражения грамматического значения, как средство для выражения грамматического значения. Названные свойства можно иллюстрировать такими примерами одёжа - одежда, видеть - вижу, голый голь. Подходов к построению морфонологии существует довольно много, вплоть до отрицания необходимости выделять морфонему в качестве отдельной единицы [Реформатский 1970: 402-409]. Многое зависит и от того, из какого раздела языкознания исследователь приходит к морфонологии. Если от фонологии, то он стремится увидеть в морфонологии те же отношения, что и в фонологии, не очень

\footnotetext{
${ }^{2}$ Сторонники «пражского» подхода к фонологии не разработали общепринятой системы обозначения архифонем, поэтому разные архифонемы часто приходится обозначать одинаково.
} 
вникая в грамматические нюансы. Те, кто теснее связан с морфологией, стремятся дать исчерпывающее описание грамматической обусловленности морфонологических чередований. Оба направления продуктивны. Морфонема включает в себя чередовательный ряд, состоящий из парадигмо-фонем.

17. Подводя итоги, следует сформулировать главную идею многоуровневой фонологии. Фонология представляет собой систему иерархических единиц, которые в зависимости от позиции реализуются рядами чередующихся членов

$$
\begin{aligned}
& \text { МФ = ПФ // ПФ //ПФ } \\
& \Pi \Phi=\text { СФ // СФ // СФ } \\
& \text { СФ = ДФ // ДФ // ДФ или СФ = ЗЯ // ЗЯ // ЗЯ } \\
& 3 Я=3 \mathrm{P}_{\mathrm{II}} / / 3 \mathrm{P}_{\mathrm{II}} / / 3 \mathrm{P}_{\mathrm{II}} \\
& 3 \mathrm{P}_{\mathrm{II}}=3 \mathrm{P}_{\mathrm{I}} / / 3 \mathrm{P}_{\mathrm{I}} / / 3 \mathrm{P}_{\mathrm{I}} \text {. }
\end{aligned}
$$

\section{Литература}

Аванесов Р.И. Фонетика современного русского литературного языка. М.: Изд-во МГУ, 1956. $240 \mathrm{c.}$

Бернштейн С. И. Основные понятия фонологии // Вопросы языкознания. 1962. №5. C. 62-80.

Горикова К.В. О фонеме в языке и речи // Slavia orientalis. Warszawa, 1980. DXXIX. No. 1/2. C. 79-83.

Ельмслев Л. Пролегомены к теории языка // Новое в лингвистике. Вып. І. М., 1960. C. 264-389.

Журавлев В.К. Понятие силы нейтрализации (к проблеме происхождения аканья) // Вопросы филологии: Сборник трудов. К 70-летию проф. А.Н. Стеценко. М., 1974. C. 59-61.

Журавлев В.К. Теория группофонем: Развитие группового сингармонизма в праславянском языке. М.: Изд-во ЛКИ, 2007. 128 с.

Златоустова Л. В., Потапова Р. К., Потапов В. В., Трунин-Донской В. Н. Общая и прикладная фонетика. М.: Изд-во МГУ, 1997. $416 \mathrm{c.}$

Касаткин Л.Л. Фонетика // Современный русский литературный язык / Под ред. П. А. Леканта. М., 1982. 399 с.

Касаткин Л. Л. О природе фонемы // Вопросы языкознания. 2009. №2. С. 92-102.

Князев С. В. О фонетических и фонологических позициях, чередованиях и признаках // Проблемы фонетики V: Сб. статей. Вып. 5 / Отв. ред. Р. Ф. Касаткина. М.: Наука, 2007. С. 53-71.

Кодзасов С. В., Кривнова О. Ф. Общая фонетика. М.: РГГУ, 2001. 592 с.

Кузнеиов П. С. Об основных положениях фонологии // Реформатский А. А. Из истории отечественной фонологии. М.: Наука, 1970. С. 470-480.

Осипов Б. И. Проблема иерархии фонологических единиц // Фонетика сегодня. Материалы докладов и сообщений VIII Международной научной конференции 2830 октября 2016 года. М.; СПб.: Нестор-История, 2016. С. 80-84. 
Панов М. В. Русская фонетика. М.: Просвещение, 1967. 440 с.

Панов М.В. Современный русский язык. Фонетика. М.: Высшая школа, 1979. $256 \mathrm{c.}$

Панов М.В. «К думанью»: Фонологическая кулибряга // Жизнь языка: памяти Михаила Викторовича Панова / Под ред. Е. А. Земской, М. Л. Каленчук. М.: Языки славянских культур; Знак, 2007. С. 469-474.

Панов М. В. Лингвистика и преподавание русского языка в школе. М.: Фонд развития фундаментальных лингвистических исследований, 2014. 272 с.

Полковникова С.А. О перцептивной функции и перцептивной позиции фонемы // Язык: изменчивость и постоянство. К 70-летию Л.Л. Касаткина / Отв. ред. М. Л. Каленчук. М.: ИРЯ РАН, 1998. С. 225-230.

Попов М. Б. Фонетика современного русского языка: Учебник. СПб.: Филологический факультет СПбГУ, 2014. 303 с.

Реформатский A.A. О соотношении фонетики и грамматики (морфологии) // Реформатский А.А. Из истории отечественной фонологии. М.: Наука, 1970. C. 398-421.

Соколянский $A$. A. Фонологическая интерпретация русского вокализма // Русский язык: исторические судьбы и современность: Международный конгресс исследователей русского языка. М., 2001. С. 244.

Соколянский A.A. Доморфологический этап русской фонологии (или О единых основаниях фонетики и фонологии) // Жизнь языка: памяти Михаила Викторовича Панова / Под ред. Е.А. Земской, М.Л. Каленчук. М.: Языки славянских культур; Знак, 2007a. С. 394-437.

Соколянский A.A. Звук речи и звук языка // Фонетика сегодня. Материалы докладов и сообщений V Международной научной конференции 8-10 октября 2007 года. М., 2007b. С. 171-173.

Соколянский $A$. A. К построению многоуровневой фонологии русского языка // Вестник Северо-Восточного государственного университета. Вып. 8. Магадан, 2007c. С. 68-75.

Соколянский A.A. Многоуровневая фонология русского языка // Русский язык: исторические судьбы и современность: III Международный конгресс исследователей русского языка (Москва, МГУ им. М.В. Ломоносова, филологический факультет, 20-23 марта 2007 г.): Труды и материалы / Составители М. Л. Ремнева, А. А. Поликарпов. М., 2007d. С. 356.

Соколянский A. A. О единых основаниях фонетики и фонологии // Проблемы фонетики V: Сб. статей. Вып. 5 / Отв. ред. Р. Ф. Касаткина. М.: Наука, 2007е. С. 107150.

Соколянский $A$. А. Модель многоуровневой фонологии русского языка. Монография. Магадан: СВГУ, 2010а. 283 с.

Соколянский A. A. Может ли лингвистика иметь свои аксиомы? // Русский язык в школе. 2010b. №6. С. 37-41.

Соколянский $A$. A. О разграничении понятий дифференциатор и синтагмо-фонема // Вестник Читинского государственного университета. 2010с. № 2. С. 111-116. 
Соколянский А. А. Долгие согласные в русском языке // Фонетика сегодня. Материалы докладов и сообщений VII Международной конференции 27-29 сентября 2013 года. М., 2013. С. 78-80.

Соколянский $A . A$. История фонетики и фонологии в России: учебное пособие. Магадан, 2016а. $126 \mathrm{c}$.

Соколянский А. А. О строении дифференциального признака (преимущественно на примере корреляции глухости / звонкости) // Вестник Северо-Восточного государственного университета. Вып. 25. Магадан, 2016b. С. 26-32.

Соколянский A.A. Типология фонологических нейтрализаций // Вестник Московского государственного областного университета. Раздел Филологические науки. 2016. №4. [Электронный ресурс]. URL: https:/evestnik-mgou.ru/ru/Articles/ Doc/779.

Трубеикой Н. С. Основы фонологии. М.: Изд-во иностранной лит-ры, 1960. 372 с.

\author{
Alexander A. Sokolyanskiy \\ North-Eastern State University \\ (Russia, Magadan) \\ sokol_2001@mail.ru \\ sokol_2001@outlook.com
}

\title{
THE PHONEME AS A RISE: THE MAIN PROVISIONS OF MULTILEVEL PHONOLOGY*
}

Inside of the Moscow Phonological School there have actually been formed two conceptions of the phonological system. The traditional doctrine was supposed to imply one phonological unit - phoneme (A. A. Reformatsky, S. P. Kuznetsov, V.N. Sidorov, L.L. Kasatkin). Later the idea of the multilevel phonology started up by references to several types of phonemes in accordance with the different functions of the sound units (S. I. Bernstein, R. I. Avanesov, M. V. Panov). Attempts to develop the ideas of the multilevel phonology can be also found in the works of the author of this article.

The author comes to the conclusion that the most adequate approach to describe the phonetic language layer is a multilevel system. It is proposed to distinguish the following units: a syllable as a unit of speech, the speech sound of the first and second kind as units of speech, the language sound as a unit intermediate between the language and the speech, a differentiator, a sintagmo-phoneme, a paradigmo-phoneme, a morphoneme as language units. Allocated units are connected to each other by the system of alternations.

The article describes the main provisions of multilevel phonology of the Russian language from the standpoint of the Moscow phonological school. The author comes to the

* The research is financially supported by the Russian Foundation for Basic Research, project No. 15-04-00338 "Multilevel phonology of the Russian language". 
conclusion that the most adequate approach to describe the phonetic language layer is a multilevel system. It is proposed to distinguish the following units: a syllable as a unit of speech, the speech sound of the first and second kind as units of speech, the language sound as a unit intermediate between the language and the speech, a differentiator, a sintagmo-phoneme, a paradigmo-phoneme, a morphoneme as language units. Allocated units are connected to each other by the system of alternations.

Key words: multilevel phonology, a speech sound, the sound of the language, a differentiator, a sintagmo-phoneme, a paradigmo-phoneme, a morpheme

\section{References}

Avanesov R. I. Fonetika sovremennogo russkogo literaturnogo yazyka [Phonetics of modern Russian literary language]. Moscow, Izd-vo Moskovskogo universiteta Publ., 1956. $240 \mathrm{p}$.

Bernshtein S. I. [The main provisions of phonology]. Voprosy yazykoznaniya. 1962. No. 5. P. 62-80. (In Russ.)

El'mslev L. [Prolegomena to a theory of language]. Novoe v lingvistike. Iss. I. Moscow, Izd-vo inostrannoi literatury Publ., 1960. P. 264-389 (In Russ.)

Gorshkova K.V. [About the phoneme in language and speech]. Slavia orientalis. Warszawa, 1980. DXXIX. No. 1/2. P. 79-83. (In Russ.)

Kasatkin L.L. [Phonetics]. Sovremennyi russkii literaturnyi yazyk [Modern Russian literary language]. Ed. P. A. Lekant. Moscow, Vysshaya shkola Publ., 1982. P. 399. (In Russ.)

Kasatkin L.L. [The nature of the phoneme]. Voprosy yazykoznaniya. 2009. No. 2. P. 92-102. (In Russ.)

Knyazev S. V. [On phonetic and phonological positions, alternations and features]. Problemy fonetiki V: Sb. statei [Problems of phonetics V. Collection of articles]. Ed. R.F. Kasatkina. In-t rus. yaz. im. V. V. Vinogradova RAN. Moscow, 2007. Iss. 5. P. 5371. (In Russ.)

Kodzasov S. V., Krivnova O.F. Obshchaya fonetika [General phonology]. Moscow, RSUH, 2001. 592 p.

Kuznetsov P. S. [On the main provisions of phonology]. Reformatskii A.A. Iz istorii otechestvennoi fonologii. Moscow, Nauka Publ, 1970. P. 470-480. (In Russ.)

Osipov B.I. [The problem of the hierarchy of phonological units]. Fonetika segodnya. Materialy dokladov i soobshchenii VIII Mezhdunarodnoi nauchnoi konferentsii 28 30 oktyabrya 2016 goda [Phonetics today. Materials of reports and reports of the $8^{\text {th }}$ International Scientific Conference on October 28-30, 2016]. Moscow, St. Petersburg, Nestor-Istoriya Publ., 2016. P. 80-84. (In Russ.)

Panov M.V. Russkaya fonetika [Russian phonetics]. Moscow, Prosveshchenie Publ., 1967. $440 \mathrm{p}$.

Panov M. V. Sovremennyi russkii yazyk. Fonetika [Modern Russian language. Phonetics]. Moscow, Vysshaya shkola Publ., 1979. 256 p.

Panov M.V. ["K duman'yu": phonological kulibryaga]. Zhizn' yazyka: pamyati Mikhaila Viktorovicha Panova [The life of language: in memoriam of Mikhail 
Viktorovich Panov]. Eds. E. A. Zemskaya, M.L. Kalenchuk. Moscow, Yazyki slavyanskikh kul'tur; Znak Publ., 2007. P. 469-474. (In Russ.)

Panov M. V. Lingvistika i prepodavanie russkogo yazyka v shkole [Linguistics and the teaching of the Russian language in school]. Moscow, Fond "Razvitiya fundamental'nykh lingvisticheskikh issledovanii” Publ., 2014. 272 p.

Polkovnikova S. A. [On perceptual function and perceptual phoneme position]. $\mathrm{Ya}$ zyk: izmenchivost' i postoyanstvo. K 70-letiyu L. L. Kasatkina [Language: variability and stability. The $70^{\text {th }}$ anniversary of the L.L. Kasatkin]. Ed. M.L. Kalenchuk. Moscow, 1998. P. 225-230 (In Russ.)

Popov M. B. Fonetika sovremennogo russkogo yazyka [Phonetics of the modern Russian language]. St. Petersburg, Filologicheskii fakul'tet SPbGU Publ., 2014. 303 p.

Reformatskii A. A. [Regarding the relationship between phonetics and grammar (morphology)]. Reformatskii A. A. Iz istorii otechestvennoi fonologii. Moscow, Nauka Publ., 1970. P. 398-421. (In Russ.)

Sokolyanskii A. A. [Phonological interpretation of Russian vocalism]. Russkii yazyk: istoricheskie sud'by i sovremennost': Mezhdunarodnyi kongress issledovatelei russkogo yazyka [Russian language: historical destinies and the present: International Congress of Russian Language Researchers]. Moscow, MGU Publ., 2001. P. 244. (In Russ.)

Sokolyanskii A. A. [Pre-morphological phase of Russian phonology (or On the common grounds of phonetics and phonology)]. Zhizn' yazyka: Pamyati Mikhaila Viktorovicha Panova [The life of language: The memory of the Mikhail Viktorovich Panov]. Eds. M. L. Kalenchuk, E. A. Zemskaya. Moscow, 2007a. P. 394-437. (In Russ.)

Sokolyanskii A. A. [Speech sound and the sound of language]. Fonetika segodnya. Materialy dokladov i soobshchenii $V$ mezhdunarodnoi nauchnoi konferentsii 8-10 oktyabrya 2007 goda [Phonetics today. Materials of reports and reports of the $5^{\text {th }}$ international scientific conference on October 8-10, 2007]. Moscow, 2007b. P. 171-173. (In Russ.)

Sokolyanskii A. A. [On building a multilevel phonology of the Russian language]. Vestnik Severo-Vostochnogo gosudarstvennogo universiteta. Iss. 8. Magadan, 2007c. P. 68-75. (In Russ.)

Sokolyanskii A. A. [Multilevel phonology of the Russian language]. Russkii yazyk: istoricheskie sud'by i sovremennost': III Mezhdunarodnyi kongress issledovatelei russkogo yazyka (Moskva, MGU im. M. V. Lomonosova, filologicheskii fakul'tet, 20-23 marta 2007 g.): Trudy i materialy [Russian language: historical destinies and the present: $3^{\text {rd }}$ International Congress of Russian Language Researchers (Moscow, MV Lomonosov Moscow State University, Faculty of Philology, March 20-23, 2007): Proceedings and materials]. Comp. M. L. Remneva, A. A. Polikarpov. Moscow, 2007d. P. 356. (In Russ.)

Sokolyanskii A. A. [On common grounds of phonetics and phonology]. Problemy fonetiki V: Sb. Statei [Problems of phonetics V: Collection of articles]. Ed. R.F. Kasatkina. In-t rus. yaz. im. V. V. Vinogradova RAN, Moscow, 2007e. Iss. 5. P. 107-150. (In Russ.)

Sokolyanskii A. A. Model' mnogourovnevoi fonologii russkogo yazyka [The model of multilevel phonology of the Russian language]. Magadan: SVGU Publ., 2010a. 283 p.

Sokolyanskii A.A. [Could linguistics have their axioms?]. Russkii yazyk $v$ shkole. Moscow, 2010b. No. 6. P. 37-41. (In Russ.) 
Sokolyanskii A. A. [On the distinction between a differentiator and a sintagmophoneme]. Vestnik Chitinskogo gosudarstvennogo universiteta. 2010v. No. 2. P. 111116. (In Russ.)

Sokolyanskii A. A. [Long consonants in the Russian language]. Fonetika segodnya. Materialy dokladov $i$ soobshchenii VII mezhdunarodnoi konferentsii 27-29 sentyabrya 2013 goda [Phonetics today. Materials of reports and reports of the $7^{\text {th }}$ International Conference on September 27-29, 2013]. Moscow, 2013. P. 78-80. (In Russ.)

Sokolyanskii A. A. Istoriya fonetiki i fonologii v Rossii [History of phonetics and phonology in Russia]. Magadan: SVGU Publ., 2016a. 126 p.

Sokolyanskii A. A. [Regarding the structure of a distinctive characteristic (mostly based on the correlation of voiced/voiceless properties as an example)]. Vestnik SeveroVostochnogo gosudarstvennogo universiteta. Iss. 25. Magadan, 2016b. P. 26-32. (In Russ.)

Sokolyanskii A. A. [The typology of the phonological neutralizations]. Vestnik Moskovskogo gosudarstvennogo oblastnogo universiteta, razdel "Filologicheskie nauki". 2016c. No. 4. URL: https://evestnik-mgou.ru/ru/Articles/Doc/779 (In Russ.)

Trubetzkoy N.S. Osnovy fonologii [Fundamentals of phonology]. Moscow, Izdatel'stvo inostrannoi literatury Publ., 1960. 372 p.

Zhuravlev V.K. [The concept of force neutralization (to the problem of the origin of Akanje)]. Voprosy filologii. Sbornik trudov. K 70-letiyu prof. A. N. Stetsenko [Questions of philology. Proceedings. To the $70^{\text {th }}$ anniversary of prof. A. N. Stetsenko]. Moscow, MGPI im. V.I. Lenina Publ., 1974. P. 59-61. (In Russ.)

Zhuravlev V.K. Teoriya gruppofonem: Razvitie gruppovogo singarmonizma v praslavyanskom yazyke [Theory of groupophonemes: The development of group synharmonism in the Proto-Slavic language]. Moscow, Izdatel'stvo LKI Publ., 2007. 128 p.

Zlatoustova L.V., Potapova R.K., Potapov V.V., Trunin-Donskoi V.N. Obshchaya i prikladnaya fonetika [General and applied phonetics]. Moscow, MGU Publ., 1997. $303 \mathrm{p}$. 